\title{
Prototipe Chamber Pengaturan Suhu, Kelembaban dan Growing LED Tanaman Aeroponic
}

\author{
Anwar Mujadin $^{1}$ \\ ${ }^{1}$ Teknik Elektro, Fakultas Sains dan Teknologi, Komplek Masjid Agung Al Azhar Kebayotan Baru \\ Jakarta Selatan, Kode Pos 12110
}

Penulis untuk Korespondensi/E-mail: amujadin@uai.ac.id

\begin{abstract}
Abstrak - Aeroponic merupakan salah satu cara bercocok tanam dengan sistem pengkabutan, dimana akar tanamannya menggantung di udara tanpa media tanah, dan kebutuhan nutrisinya dipenuhi dengan cara spraying ke akarnya. Prototipe berbentuk chamber, hasil penelitian menunjukan, penyemprotan nutrisi ke akar sayuran disertai dengan pengendalian paparan cahaya tumbuh (light growing LED), tanaman mampu menyerap nutrisi dan berkembang secara optimal dengan data hasil pengamatan selama satu minggu berturut turut: ukuran kecambah naik $2 \mathrm{~cm}$ per hari, berat basah kecambah rata-rata 26 gram tiap pot.
\end{abstract}

Kata Kunci: Aeroponics Chamber, Growing LED, Mist Maker

Abstract-Aeroponic is one way farming using fogging system, where the roots of the vegetables hangs in the air without soil media, and nutrient requirement accomplished by spraying into root. Prototypes are chamber, observational result shown that the nutrient spraying into root of vegetables accompanied by esposure growing LED, the plant can be absorb nutrient optimally. With the observed data for one week respectively: sprout size ascends $2 \mathrm{~cm}$ per day, every pots sprout wet weight average 26 grams.

Keywords: Aeroponics Chamber, Growing LED, Mist Maker

\section{PENDAHULUAN}

\begin{abstract}
$\mathrm{A}$ eroponic merupakan salah satu cara budidaya tanaman berbasis air. Kalau dilihat dari katakata penyusunnya, yaitu terdiri dari aero ditambah phonic. Aero berarti udara, phonik artinya cara budidaya, arti secara harafiah cara bercocok tanam di udara, atau bercocok tanam dengan system pengkabutan, dimana akar tanamannya menggantung di udara tanpa media tanah, dan kebutuhan nutrisinya dipenuhi dengan cara spraying ke akarnya [1].
\end{abstract}

Penerapan sistem aeroponic akan mengurangi ketergantungan ketersediaan tanah dan tidak dibutuhkan rotasi lahan. Dengan aeroponic dipastikan bisa menanam sepanjang musim tidak tergantung pada iklim, produktivitas tidak menurun walaupun pada musin penghujan (mendung) atau musim kering (panas).

Produk aeroponic bersih dan sehat. Budidaya aeroponic memerlukan green house di area sempit (kontener) dengan suplai listrik yang relatif besar.
Nutrisi, aeroponic terpenuhi karena kita bisa mengaturnya dengan ukuran (formula). Budidaya aeroponic aman oleh hama dan penyakit. Bisa dipindah-pindah tanpa mengganggu pertumbuhan, saat pindah tanam bisa langsung tumbuh tanpa aklimatisasi.

Pada Gambar 1 diperlihatkan tanaman aeroponic (akar tergantung diudara)[2].

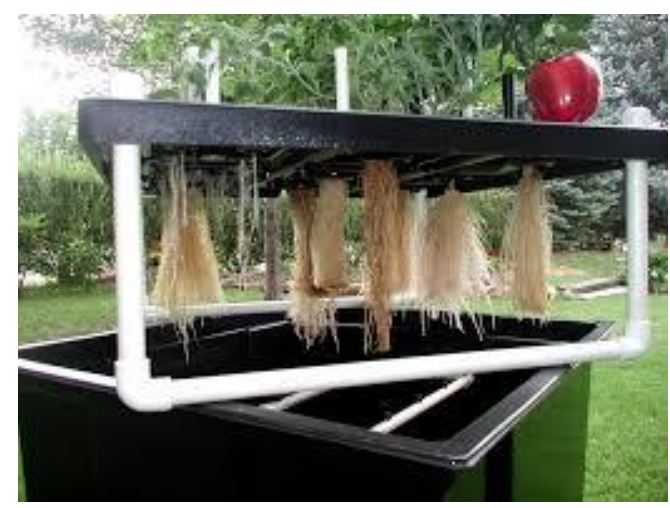

Gambar 1. Tanaman aeroponic (akar tergantung diudara) [2]. 


\section{TINJAUAN PUSTAKA}

\section{Teknis dan Peralatan Budi Daya Tanaman Secara Aeroponics}

Teknologi penanaman dengan teknik aeroponik merupakan teknologi bercocok tanam sayuran yang sudah mulai banyak dilakukan oleh para penggemar tanaman. Selain caranya yang dibuat cukup sederhana dan alat yang digunakan tidak sulit didapat, teknik aeroponik ini juga dapat dilakukan di teras rumah maupun di dalam rumah.

Peralatan yang dibutuhkan untuk aeroponics diperlihatkan pada Gambar 2 berikut [3].

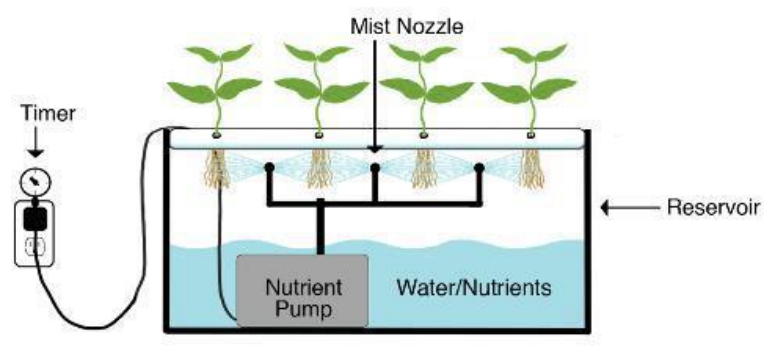

Gambar 2. Peralatan aeroponic [3].

\section{Light Growing LED}

Lampu light emitting diode (LED) untuk pertumbuhan tanaman ditemukan untuk pertama kalinya oleh perusahaan Solar Oasis pada tahun 2002 [1]. LED memiliki warna cahaya sangat beraneka ragam dan masing-masing memiliki panjang gelombang sendiri. Lampu-lampu yang digunakan sebagai lampu penumbuh tanaman (growing LED) memiliki panjang gelombang cahaya mulai dari 380 nanometer $(\mathrm{nm})$ yang disebut cahaya ultra violet, hingga $880 \mathrm{~nm}$ yang disebut cahaya infra red. Tanaman membutuhkan cahaya yang terlihat mata (visible light) dengan spektrum antara $400 \mathrm{~nm}-700 \mathrm{~nm}$.

Penyerapan chlorophyl menghasilkan pertumbuhan yang kuat pada spektrum antara $390 \mathrm{~nm}$ - 510 nm. Spektrum $610 \mathrm{~nm}-700 \mathrm{~nm}$ merupakan spektrum utama bagi proses photosintesa. Cahaya merah tua, yang terletak pada spektrum $700 \mathrm{~nm}$ $730 \mathrm{~nm}$ sangat baik untuk proses berbunga. Dari spektrum di atas, dibuatlah berbagai jenis lampu LED untuk tanaman, baik untuk tanaman secara umum maupun yang dirancang untuk jenis tanaman tertentu. Akan tetapi agar dapat tumbuh secara sehat, tanaman sebaiknya disinari lampu LED dengan total penyinaran tidak melampui $14-16$ jam setiap harinya [4].

Pada Gambar 4 diperlihatkan growing LED [4].

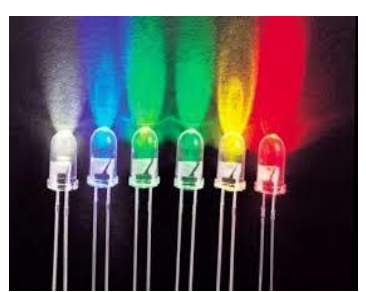

a.

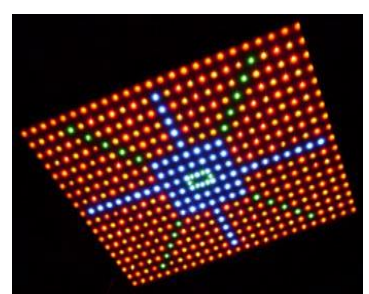

b.
Gambar 3. (a) led yang belum disusun (b) LED yang telah disusun untuk light growing [4]

Spektrum cahaya dengan panjang gelombang memberikan efek pertumbuhan pada tanaman. Pada Gambar 2.4 diperlihatkan penyerapan panjang gelombang untuk pertumbuhan tanaman [5].

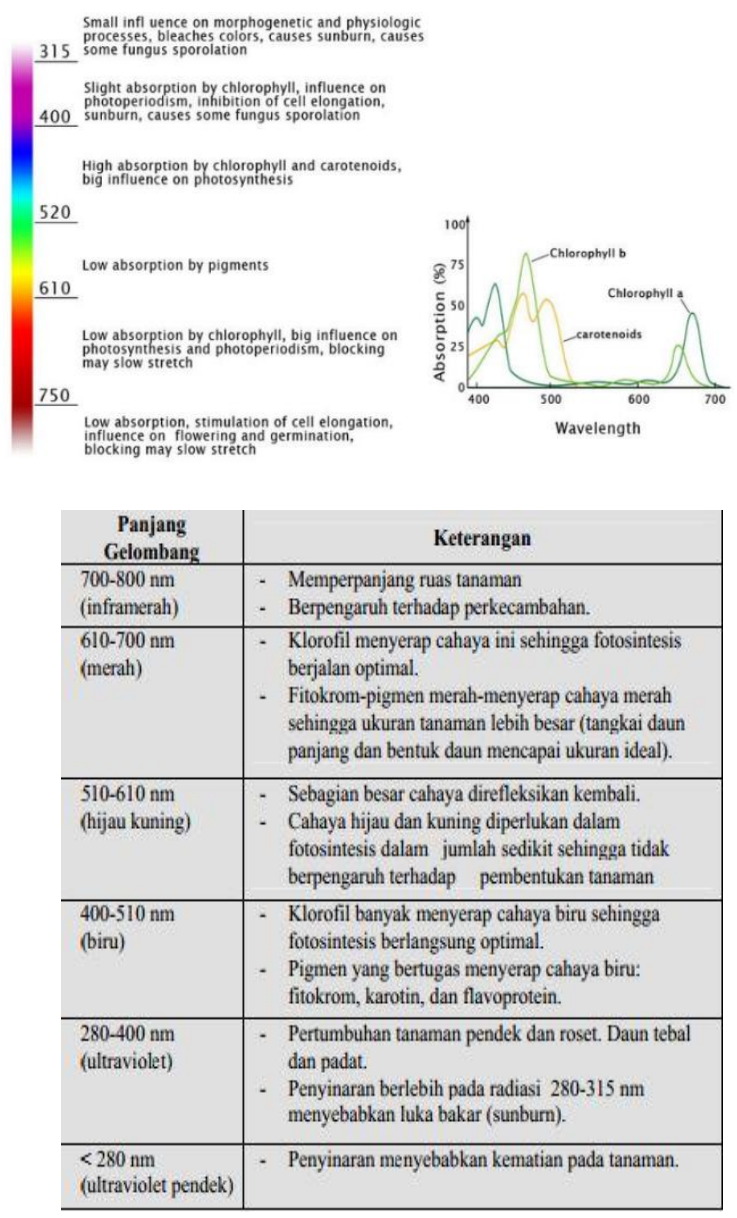

Gambar 4. Penyerapan panjang gelombang untuk pertumbuhan tanaman [5]. 
Tanaman dapat diletakan didalam rumah, cahaya LED dapat menggantikan cahaya matahari untuk keperluan proses photosintesa.

Pada Gambar 5 diperlihatkan tanaman dapat diletakan didalam rumah dan cahaya LED sebagai sinar proses photosintesa.

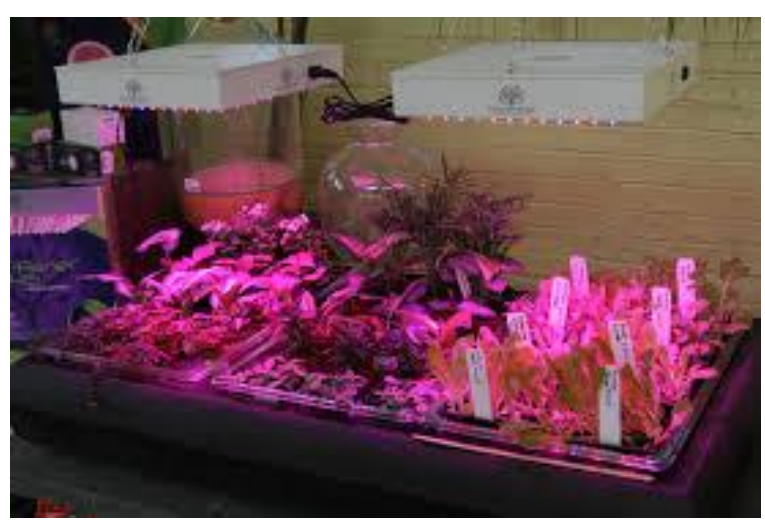

Gambar 5. Budidaya tanaman didalam rumah cahaya LED sebagai sinar proses photosintesa

\section{Piezoelectric Buzzer Pembuat Kabut}

Kabut adalah kumpulan tetes-tetes air yang sangat kecil yang melayang-layang di udara. Kabut mirip dengan awan, perbedaannya, awan tidak menyentuh permukaan bumi, sedangkan kabut menyentuh permukaan bumi. Biasanya kabut bisa dilihat di daerah yang dingin atau daerah yang tinggi. Pada umumnya, kabut terbentuk ketika udara yang jenuh akan uap air didinginkan di bawah titik bekunya. Kabut juga dapat terbentuk dari uap air yang berasal dari tanah yang lembab, tanaman-tanaman, sungai, danau, dan lautan. Uap air ini berkembang dan menjadi dingin ketika naik ke udara. Udara dapat menahan uap air hanya dalam jumlah tertentu pada suhu tertentu. Udara pada suhu $30^{\circ} \mathrm{C}$ dapat mengandung uap air sebangyak 30 gr uap air per m3, maka udara itu mengandung jumlah maksimum uap air yang dapat ditahannya. Volume yang sama pada suhu $20^{\circ} \mathrm{C}$ udara hanya dapat menahan 17 gr uap air. Sebanyak itulah yang dapat ditahannya pada suhu tersebut. Ketika suhu udara turun dan jumlah uap air melewati jumlah maksimum uap air yang dapat ditahan udara, maka sebagian uap air tersebut mulai berubah menjadi embun. Ukuran koloid dari kabut adalah $50 \mathrm{~nm}$ dan dapat melayang diudara seperti halnya asap [6].

Dengan teknologi piezoelectric yang bekerja pada frekuensi 1.5 Mhz mampu menciptakan air biasa menjadi kabut air. Air akan digitarkan pada frekuensi $1.5 \mathrm{Mhz}$ sehingga terurai menjadi partikel kecil seukuran $50 \mathrm{~nm}$ (kabut), tranducer ini tidak ketergantungan pada suhu dan tekanan seperti sifat alamiah kabut.

Ultrasonic Mist Maker adalah Alat yang dapat merubah air biasa menjadi awan kabut seperti dinginnya es yang biasa terlihat pada biang es. Alat ini bekerja menggunakan proses ultrasonic atomization yang mengubah air menjadi kabut [7]. Pada Gambar 6 diperlihatkan (a)tranducer mist maker dan (b) kabut yang dihasilkan.

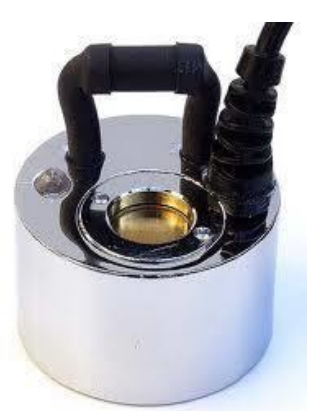

(a)

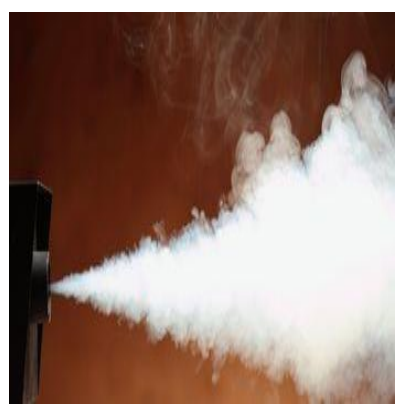

(b)
Gambar 6 (a) Mist maker tranducer

(b) Kabut air buatan dari mist maker [7].

\section{METODE PENELITIAN}

Membuat sebuah chamber, untuk karakterisasi tanaman aeroponic, terutama ditinjau dari suhu, kelembaban, pemberian nutrisi (penyemprotan ke akar) dan pengaturan paparan cahaya tumbuh ( growing LED). Pengujian dilakukan pada pertumbuhan kecambah Kacang merah, kacang hijau dan kacang tanah. Tujuan yang ingin dicapai adalah mengetahui komposisi spectrum cahaya yang paling tepat untuk laju fotosintesis pada tanaman dan mengetahui faktor-faktor yang mempengaruhi pertumbuhan tanaman.

\section{HASIL DAN PEMBAHASAN}

Rancang bangun prototipe chamber dilakukan secara bertahap terdiri dari unit sprayer (pemberian nutrisi), unit growing $L E D$, unit pengatur suhu (kipas dan exhause), unit pengatur kelembaban (mist maker), dan unit sistem kendali utama (mikrokontroller).

Chamber bekerja semi otomatis, mampu diprogram sesuai dengan karakter tumbuhan yang akan diuji. 
Pada Gambar 7 diperlihatkan hasil pengembangan prototipe unit sprayer (pemberian nutrisi).

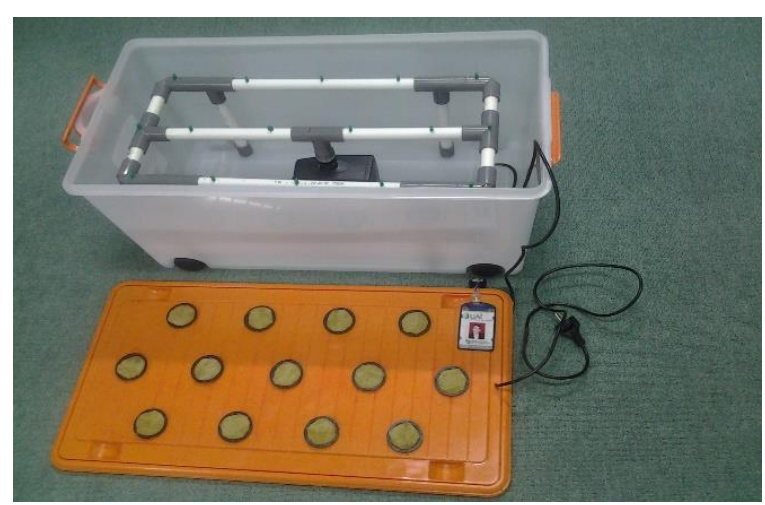

Gambar 7. prototipe unit sprayer

Pada Gambar 8 diperlihatkan hasil pengembangan prototipe unit growing LED.

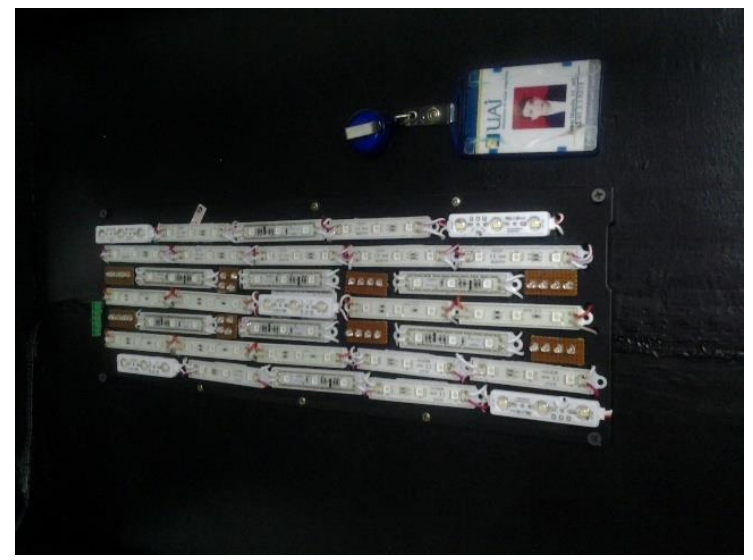

Gambar 8. Hasil pengembangan prototipe unit growing LED.

Pada Gambar 9 diperlihatkan hasil pengembangan prototipe chamber.

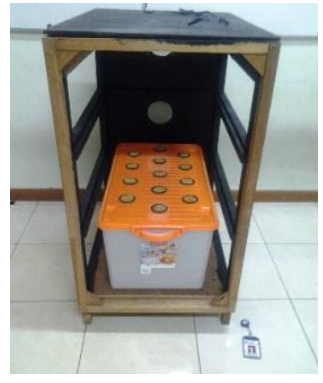

a.

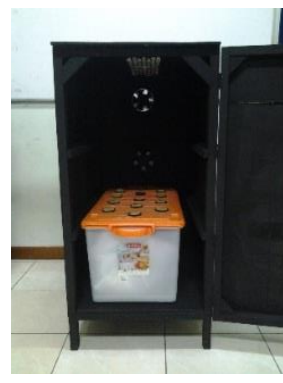

b.
Gambar 9. diperlihatkan hasil pengembangan prototipe chamber. (a) Unit chamber $75 \%$ finishing (b) Unit chamber $100 \%$ finishing
Prototipe (chamber) diujikan pada pertumbuhan kecambahan kacang hijau, kacang tanah dan kacang merah. Cahaya growing LED dipaparkan dengan komposisi intensitas cahaya biru (15.000 lux), cahaya merah (12.000 lux), cahaya putih (7500 lux), dan cahaya ultra violet (1.000 lux). Media ditempatkan kapas bernutrisi dan tidak bernutrisi (hanya air), suhu diatur pada $25^{\circ} \mathrm{C}$ dengan kelembaban diatas $80 \%$, diuji dalam kurun waktu 1 minggu.

Pada Gambar 10 diperlihatkan pengujian pertumbuhan kecambahan di dalam chamber.

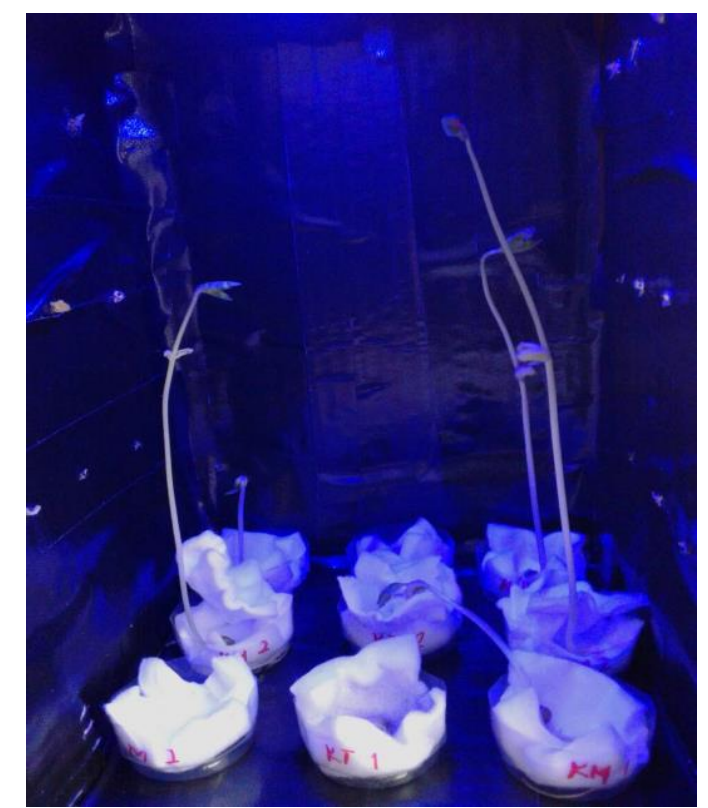

Gambar 10. Pengujian pertumbuhan kecambahan di dalam chamber.

Pada Gambar 11 diperlihatkan tabel dan grafik hasil pengukuran panjang kecambah selama 1 minggu.

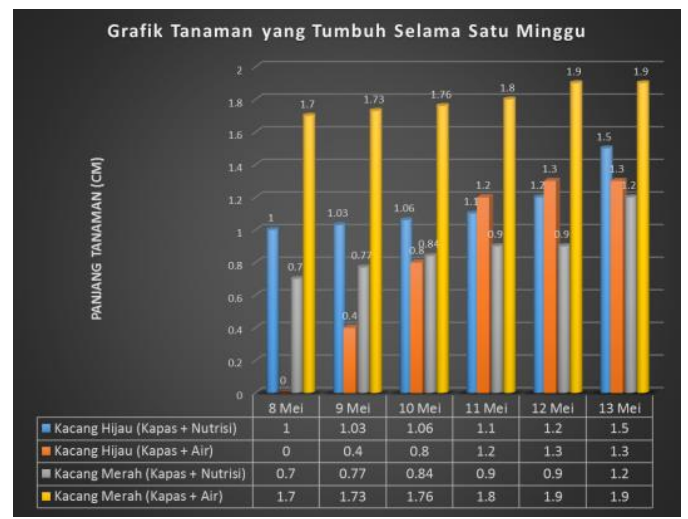

Gambar 11. Tabel dan grafik hasil pengukuran panjang kecambah selama 1 minggu 
Dari Gambar 11 Tabel dan grafik pertumbuhan kecambah diperlihatkan kenaikan pertumbuhan panjang kecambah rata-rata adalah $2 \mathrm{~cm}$ perhari. dan berat basah kecambah basah 26 gram tiap pot.

\section{KESIMPULAN}

Komposisi intensitas cahaya growing LED yang baik bagi fotosintesis tanaman adalah sama. Cahaya yang paling baik untuk fotosintesis adalah cahaya merah dan biru. klorofil paling kuat menyerap cahaya merah $(630-700 \mathrm{~nm})$ dan cahaya biru (450$480 \mathrm{~nm})$.

Fotosintesis pada tanaman selain dipengaruhi oleh cahaya juga dipengaruhi oleh ketersedian $\mathrm{CO}_{2}$ dan $\mathrm{O}_{2}$, suhu, kembaban udara.

Kebersihan media tanam, nutrisi, air, dan $\mathrm{pH}$ media tanam menentukan kembang tumbuh masingmasing tanaman.

Kecambah yang diletakkan pada media dengan kelembaban tinggi lebih cepat pertumbuhannya dibandingkan dengan kecambah yang diletakkan pada media dengan kelembaban rendah.

Wadah penumbuhan yang hanya $5 \mathrm{~cm}$ tidak dapat menjaga batang kacang untuk tetap tumbuh secara tegak, batang kecambah akan tumbuh lebih cepat namun lemah dan daunnya berukuran kecil, tipis dan berwarna pucat.

Karena media yang digunakan kapas, kacang tidak mendapat cukup nutrisi untuk menunjang pertumbuhannya karena kacang kekurangan unsur hara untuk membentuk energi yang dibutuhkan
Kenaikan pertumbuhan panjang kecambah rata-rata adalah $2 \mathrm{~cm}$ perhari. dan berat basah kecambah basah adalah 26 gram tiap pot.

\section{UCAPAN TERIMA KASIH}

Penelitian Ini Didukung Oleh Prodi Elektro Fakultas Sains Dan Teknologi Universitas Al Azhar Indonesia, Research Grant 2014-2015.

\section{DAFTAR ACUAN/PUSTAKA}

[1] Cara Tanam Aeroponics, http://indoagrow.wordpress.com, 2014. (diakses pada 24 Sptember 2014).

[2] Apa itu aeophonics, http://aeroponikleo.blogspot.com, 2014. (diakses 23 Sept 2014).

[3] Soil Aeroponic Cultur, http: //syekhfanismd.lecture.ub.ac.id, 2014. (diakses pada 24 Sptember 2014).

[4] Light Growing Led, http://atmonobudi.wordpress.com, 2013. (diakses pada 24 Sep 2014).

[5] Sun Spectrum LED, http://www.ledgrowlightsonline.com, 2014, (diakses pada 25 Sept 2014).

[6] Nahvi Mahmood \& Edminister, Josep A 2010, Electric Circuits, Schaum Series, Singapore: McGraw-Hill.

[7] Hanari Gunawan, Malvino. 1984. "Prinsipprinsip Elektronik edisi kedua". Erlangga. 1984. 